\title{
Depression and attachment: how do personality styles and social support influence this relation?
}

\author{
Paula Dagnino, ${ }^{1,2}$ Carola Pérez, ${ }^{3}$ Adriana Gómez, ${ }^{4}$ Sergio Gloger, ${ }^{5}$ Mariane Krause ${ }^{4}$ \\ ${ }^{1}$ Psychiatry Department, Pontificia Universidad Catolica de Chile, Santiago; ${ }^{2}$ Psychology Faculty, Universidad Gabriela Mistral, \\ Santiago; ${ }^{3}$ Department of Psychology, Universidad del Desarrollo, Santiago; ${ }^{4}$ Psychology School, Pontificia Universidad Catolica de Chile, \\ Santiago; ${ }^{5}$ Psicomedica Clinical \& Research Group, Santiago, Chile
}

\begin{abstract}
The purpose of this study is to improve the current understanding of the relation between depression and attachment through the evaluation of the role of personality styles (dependent $v s$ self-critical) and social support in this association. These variables were studied in a clinical sample of 70 depressed outpatients ( $83 \%$ women; $\mathrm{M}=41.47$ years, $\mathrm{SD}=12.91$ ). Depressive symptomatology was assessed through the Beck Depression Inventory, adult attachment through the Experiences in Close Relationships Scale, social support through the Social Support Questionnaire and dependency and self-criticism through the Depressive Experiences Questionnaire. Mediational and moderation regression analyses were performed. Results show that the association between the dimensions of attachment (anxiety and avoidance) and depression was partially mediated by self-criticism. Furthermore, results demonstrate the role of social support as a moderating variable: when the level of satisfaction with social support was low and the anxiety dimension in the attachment scale was high, as avoidance increased, depressive symptoms increased as well. Results are

Correspondence: Paula Dagnino, Psychiatry Department, Pontificia Universidad Catolica de Chile, Marcoleta 381, 7810000 Santiago, Chile. discussed in relation to their importance for understanding the complex interplay of the variables involved in depression.
\end{abstract}

E-mail: paula.dagnino@ugm.cl

Acknowledgements: this study received support from the Millennium Scientific Initiative, Projects \# NS100018 and \# IS130005, from the National Strategy for Innovation of the Ministry of Economy, Promotion, and Tourism (Innovation for Competitiveness Fund) and from the Universidad Gabriela Mistral - Project $\mathrm{N}^{\circ}$ 10112 .

Contributions: all of the authors contributed to the design, interpretation of data for the work; they also critically revised it for important intellectual content and participated in the final approval of the version to be published, and ensured the integrity of the work.

Conflict of interest: the authors declare no potential conflict of interest.

Note: this work was presented at the $46^{\text {th }}$ Annual International Meeting of the Society for Psychotherapy Research at Philadelphia, PA, USA, June 24-27, 2015, entitled: Adult attachment, social network and personality dimensions: their relation with depression.

Citation: Dagnino, P., Pérez, C., Gómez, A., Gloger, S., \& Krause, M. (2017). Depression and attachment: how do personality styles and social support influence this relation? Research in Psychotherapy: Psychopathology, Process and Outcome, 20(1), 53-62. doi: 10.4081/ripppo.2017.237

Received for publication: 9 November 2016.

Revision received: 13 February 2017.

Accepted for publication: 28 February 2017.

This work is licensed under a Creative Commons Attribution NonCommercial 4.0 License (CC BY-NC 4.0).

CCopyright P. Dagnino et al., 2017

Licensee PAGEPress, Italy

Research in Psychotherapy:

Psychopathology, Process and Outcome 2017; 20:53-62

doi:10.4081/ripppo.2017.237
Key words: Depression; Attachment; Social support; Dependency and self-criticism.

\section{Introduction}

Given that depression is the most commonly occurring, serious, and recurrent mental disorder worldwide (WHO, 2012; Kessler \& Bromet, 2013), large amounts of resources have been invested in trying to understand its complexity.

In the search for explanations, the relation between attachment and depression has received special attention. Attachment insecurities -based on negative models of self and others, and both intra- and interpersonal regulatory deficits rooted in discouraging experiences with unavailable, rejecting, or neglectful attachment figures- puts a person at risk for psychological disorders (Mikulincer \& Shaver, 2007).

Researchers have extended Bowlby's concepts from the infant to the adult relationship domain (e.g. Brennan, Clark, \& Shaver, 1998). Adult attachment insecurities can be described in terms of two dimensions (Brennan, Clark, \& Shaver, 1998): i) adult attachment anxiety is defined as the fear of rejection and abandonment. People with anxious attachment tend to develop a negative internal working model of self (Pietromonaco \& Barrett, 2000) and perceive less self-efficacy, resulting - in some cases - in psychopathologies such as depressive reactions; ii) adult 
attachment avoidance is characterized by a fear of intimacy and discomfort with closeness and dependence. They tend to block normal emotions having difficulties to deal with adversities (Mikulincer \& Shaver, 2007).

Several studies have shown the relation of these maladaptative attachment styles to depression (e.g. Bifulco, Moran, Ball, \& Bernazzani, 2002; Gnilka, Ashby, \& Noble 2013; Jinyao et al., 2012; López, Mauricio, Gormley, Simko \& Berger, 2001; McCarthy, 1999; Wei, Heppner, Rusell \& Young, 2006), but more research is needed to establish how attachment and depression relate to other variables that have been studied, such as personality styles or social support.

In another attempt to better understand the complexity of depression, two major types of experiences that characterize psychopathology have been identified: i) disruptions of gratifying interpersonal relationships (for example, object loss), and ii) disruptions of an effective and essentially positive sense of self (for example, failure).

Several researchers belonging to different theoretical traditions (e.g. Arieti \& Bemporad, 1980; Beck, 1967) have characterized depressed patients who are primarily responsive to one or the other of these two types of experiences. Blatt (1995; Blatt, Quinlan, Chevron, McDonald, \& Zuroff, 1982), from a psychoanalytic cognitive-developmental standpoint, considers that some depressed patients show predominantly self-critical personality dimensions while others have a tendency to display a dependent personality style. The dependent personality style (called anaclitic) can be seen in patients who are preoccupied primarily with issues of relatedness and use mainly avoidant defenses (e.g. withdrawal, denial, or repression). On the other hand, the self-critical (or introjective) style is found in patients who are preoccupied with establishing and maintaining a viable sense of self using counteractive defenses (projection, rationalization, reaction formation, etc.) (Reis \& Grenyer, 2002). People with a self-critical style have been shown to be the most vulnerable to depression, because they are exposed to failure stress events that, at the same time, lead to difficulties in the interpersonal area, which in turn diminishes social support (Mongrain, 1998; Priel, \& Besser, 2000; Shahar, 2001; Shahar, Blatt, \& Zuroff, 2007; Zuroff, Mongrain, \& Santor, 2004).

Blatt and Homann (1992) suggest that the developmental origins of these two personality styles that lead to two types of depression (anaclitic or dependency and introiective or self-criticism) may depend on different attachment styles, with an anxious or ambivalent insecure attachment possibly leading to a depression focused on issues of dependency, loss, and abandonment, and an avoidant insecure attachment potentially resulting in a depression focused on issues of self-worth. In line with this, several studies (e.g. Reis and Grenyer, 2002; Zuroff and Fitzpatrick, 1995) have confirmed these findings, suggesting that personality styles could have a mediating role between attachment and depression.
Blatt's formulation of personality (1974) also regards the social context as playing an important role in triggering depression. Specifically, he relates this association to the stress-diathesis model (Zubin \& Spring, 1977), according to which psychopathology results from the co-occurrence of external stress and predisposing biological or psychological traits.

Scheff (2001) proposes that the patient's current social milieu, specifically a lack of secure bonds in his or her immediate social network, is a relevant component of depression. This lack of secure bonds may function as a feedback loop where depressed affect leads to alienation from others, which in turn leads to more intense depression.

Some studies have found that social support has an independent main effect on depression, predicting lower levels of depression (Belsher \& Costello, 1998; Kessler, 1997; Paykel, 2003). In general, studies have considered withdrawal from social interaction linked to depressive symptoms (e.g. Coyne, 1976a, 1976b; Henrich, Blatt, Kuperminc, Zohar, \& Leadbeater, 2001; Joiner, 2002).

On the other hand, fewer studies have explored the relationship between maladaptative attachment styles and social dimensions. Mallinckrodt and Wei (2005) found that both attachment anxiety and avoidance were negatively related to perceived social support; but when both attachment dimensions are considered as predictor of perceived social support, only attachment avoidance was negatively related to it. These results could suggest that social dimensions could have a moderating role between attachment and depression.

When considering personality styles in relation to social support. Patients who show high perfectionism (self-criticism) have been shown to have a more limited social network; they have been described as being more socially isolated (Alden \& Bieling, 1996), distant, and cold towards others (Dinger et al., 2014) and experiencing less pleasure in social interactions (Zuroff \& Fitzpatrick, 1995). On the other hand, anaclitic people have problems expressing their anger toward others, they need to please others, and they do that by placing others' needs first. They can even be called Exploitable (Alden \& Bieling, 1996) meaning a combination of nonassertive and overly nurturing behavior.

Nonetheless, two facets have been identified within the DEQ Dependency scale that appear to assess different levels of interpersonal relatedness: Dependence and Relatedness. The first refers to expressing feelings of helplessness, fears about separation and rejection; and intense, broadranging concerns about possible loss unrelated to a particular person. The later refers feelings of loneliness in reaction to rupture of a particular relationship. In this sense, relatedeness, could be healthier aspect, and it has shown to have significantly higher correlations with measures of psychological well-being, especially in women (Blatt, 1995)

The main purpose of this study is to examine the relationship between the described variables conjointly, in a clinical sample. Specifically, we are addressing the ques- 
tion of how personality styles and social support may influence the association of maladaptive attachment patterns and depression; assuming that this variables act by different processes (mediating and moderating). Our specific aims are to determine: i) if avoidant as well as anxious attachment patterns are related to depression (Figure 1A); ii) if personality styles (dependency and self-criticism) mediate the relation between attachment patterns and depression (Figure 1B); and iii) if social support (size of the social network and satisfaction with one's social support) have an interactional role in the relation between attachment patterns and depression (Figure 1C).

Consistently with these aims, the following hypotheses were tested: i) attachment patterns (anxious and avoidant) will be related to depression; ii) the dependency personality style will be related to the anxious attachment pattern, and the self-criticism style will relate to both maladaptive attachment styles (anxious and avoidant), and the relation between attachment style and depression will be mediated by self-criticism; iii) the relation between attachment style and depression will depend on perceived social support, with the association being stronger when the levels of perceived support are lower.

\section{Materials and Methods}

\section{Participants}

Participants were 70 adult outpatients of a mental health clinic in Santiago, Chile (Table 1). The clinic has for a decade been a referral center for the treatment of depression and has implemented a protocolized diagnostic process. All the selected subjects had Major Depressive Disorder diagnosis according to ICD-10 criteria (WHO, 1992). All participants had recently started a psychotherapy process and $95.7 \%$ of them were receiving pharmacotherapy as well (there are no statistically significant differences in pharmacological treatment between genders, $\left.\chi^{2}(1, \mathrm{~N}=70)=0.65, \mathrm{P}=.72\right)$.

Regarding their history of mental health problems, $52.9 \%$ of the participants reported having received some form of psychotherapy in the past (there are no statistically significant differences between genders, $\chi^{2}(1, \mathrm{~N}=70)=0.08$, $\mathrm{P}=.77$ ), and $61.4 \%$ had received pharmacological treatment in the past (there are no statistically significant differences between genders, $\left.\chi^{2}(1, \mathrm{~N}=70)=0.45, \mathrm{P}=.50\right)$.

\section{Measurements}

\section{Beck Depression Inventory}

Beck Depression Inventory (BDI-I-A; Beck et al., 1961) is a self-administered questionnaire that measures depressive symptoms in adults and adolescents. This questionnaire has previously been used in Chile (Alvarado, Vega, Sanhueza, \& Muñoz, 2005; Santander, Romero, Hitschfeld, \& Zamora, 2011, among others). Valdés et al. (unpublished material), using a Chilean sample, found that it has a one-factor structure. In the present study, the scale had a Cronbach's alpha of .85 .
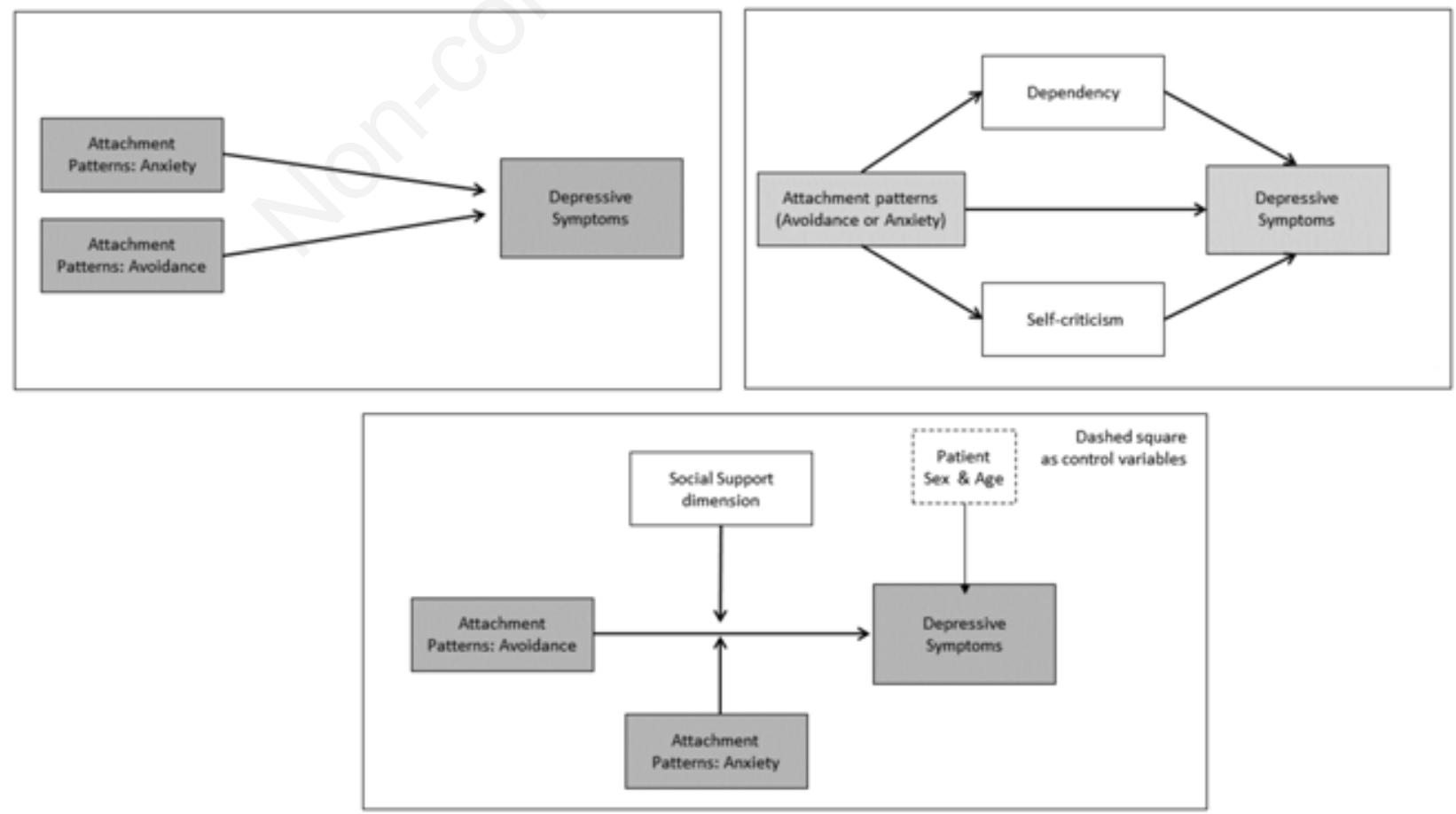

Figure 1. Graphical view of study aims. 


\section{Depressive Experience Questionnaire}

Depressive Experience Questionnaire (DEQ; Blatt, D'Afflitti, \& Quinlan, 1976) is a self-report questionnaire that measures a person's vulnerability to two types of depressive experience: anaclitic and introjective. The items yield factor scores in three dimensions: dependency, selfcriticism, and efficacy. Blatt et al. (1982) report Cronbach alphas of $.81, .80$, and .72 for the dependency, criticism, and efficacy scales. In 1999, Anez and Paris translated the questionnaire into Spanish, and this version was adapted for Chile by Rost \& Dagnino (2011).

\section{Experience in Close Relationships Scale}

Experience in Close Relationships Scale (ECR) (Brennan, Clark \& Shaver, 1998) assesses the attachment style of individuals in their romantic relationships. Two dimensions comprise the scale: i) anxiety and ii) avoidance. This scale has been used to measure attachment in Chilean samples, reaching reliability indexes of .84 for the anxiety scale and .83 for the avoidance scale (Guzmán \& Contreras, 2012). In the present study, the scales showed good reliability (Cronbach's alpha $=.86$ for the avoidance scale and $=.87$ for the anxiety scale).

\section{Social Support Questionnaire short form}

Social Support Questionnaire short form (SSQ-6; Sarason, Sarason, Shearin \& Pierce, 1987) consists of 6 items that must be answered in terms of two questions. The first indicates the number of people that the respondent perceives as willing to help and/or support him/her in the situation described in each item (Size of social network score). The sec- ond question targets the respondent's overall satisfaction with the social support received from the people who help and/or support him/her in a given situation (Satisfaction score). Regarding the validity of the instrument, Sarason et al. (1987) report that the SSQ-6 has high correlation with the original scale (.91 and .93). The instrument was translated into Spanish. In the present study, the scales showed adequate reliability (Cronbach's alpha $=.77$ for the network size scale and $=.84$ for the satisfaction scale).

\section{Procedures}

Participants were invited to enroll in this study when receiving psychological assistance at the health center. Those who agreed to participate signed Informed Consent forms (approved by the Ethical Committee of the Clinic) and completed the BDI, SSQ-6 and attachment questionnaires prior to the first session. The DEQ was completed by participants at home and returned to the researchers at the beginning of the second psychotherapy session.

\section{Data analysis}

Descriptive statistics of the study variables were calculated, comparing by gender, and Spearman correlations were estimated between variables.

\section{Mediational model}

Following the indications issued by Mackinnon (2008), we developed two mediational models. In the first step, three regression equations were estimated. Each of these regression equations was estimated using SPSS-v15 (OLS estimation).

Table 1. Participants $(n=70)$.

\begin{tabular}{lccc}
\hline & \% & M & SD \\
\hline Gender & & & 12.97 \\
Women & 83 & 41.50 & 13.18 \\
Men & 17 & & - \\
\hline Marital status & & - & - \\
Married/had live-in partners & 47.5 & - & - \\
Single & 39.1 & - & - \\
Divorced/separated & 8.7 & - & - \\
Widows/widowers & 4.3 & - & - \\
\hline Schooling & & - & - \\
Completed only primary school & 4.3 & - & - \\
Attended secondary education & 34.7 & - & - \\
Attended a vocational technical education institution & 18.8 & & - \\
Higher education & 42 & - & - \\
\hline Occupation & & - & - \\
Stay at home women & 15.4 & - & - \\
Students & 9.2 & - & - \\
Employees & 49.2 & - & - \\
Self-employees & 12.3 & -2.2 & \\
Unemployed & 4.6 & & \\
Retired & & & \\
\hline
\end{tabular}

M, mean; SD, standard deviation. 
In the second step, the parameters of the total and mediated effect (parameters value, errors, and signification) were estimated based on the value of the step one parameters. In this study, we applied a bootstrapping method (1.000 boot resample, OLS estimation) to measure the parameters' product terms (ab) as well as their errors and confidence intervals $(95 \% \mathrm{CI})$, using the SPSS syntax developed by Preacher \& Hayes (2008, SPSS INDIRECT Macro Syntax; http://www.afhayes.com/spss-sas-andmplus-macros-and-code.html).

The diagrams presented (Figures 2 and 3) establish relationships between variables and contain the parameters of the regression equations estimated. Additionally, indirect effects and total effects (bootstrapping method) are reported for each model.

\section{Interactional effects}

The regression analysis with interaction procedures suggested by Aiken and West (1991) was used. Two independent regression models were estimated. Patient age and sex were included as control variables. The significance levels of the interaction components were evaluated.

If a three-way interaction was statistically significant, four partial regression equations were estimated in order to explain the relationship between the predictor variables (Low and High values of attachment dimensions) and criterion (Depressive Symptomatology) at each level of the moderator (Low and High Network satisfaction). The high and low variable levels were estimated depending on whether their values were one standard deviation above or below the average (respectively).

\section{Results}

\section{Descriptive statistics}

Means, standard deviations, and correlations of all measures appear in Table 2. No significant differences
$(\mathrm{P}>.05)$ are observed when comparing the study variables by gender.

Bivariate correlations show that depression is related to self-criticism and marginally $(\mathrm{P}=.053)$ with avoidance. Self-criticism was found to be linked to both dimensions of attachment (anxiety and avoidance). Additionally, the attachment avoidance dimension was inversely associated with both social network variables (size and satisfaction).

\section{Mediational model}

The mediational role of dependency and self-criticism variables in the Attachment-Anxiety and Depression relationships is presented in Figure 2. The parameters of the effect mediated through Dependency $\left(\mathrm{M}_{1}\right)$ were: $\mathrm{a}_{1} \mathrm{~b}_{1}$ coefficient $=-0.34, \mathrm{SE}=.60,95 \% \mathrm{CI}-0.82$ to 1.59 . Additionally, the parameters of the effect mediated through Self-criticism $\left(\mathrm{M}_{2}\right)$ were: $\mathrm{a}_{2} \mathrm{~b}_{2}$ cefficient $=2.34, \mathrm{SE}=.86$, $95 \%$ CI 0.98 to 4.41 . The parameters of total effects were: coefficient $=2.68, \mathrm{SE}=1.06,95 \% \mathrm{CI} 0.79$ to 5.05 .

The mediational role of the dependency and self-criticism variables in the Attachment-Avoidance and Depression relationships is presented in Figure 3. The parameters of the effect mediated through Dependency $\left(M_{1}\right)$ were: $a_{1} b_{1}$ coefficient $=-0.02, S E=0.13,95 \%$ CI 0.15 to .33 . The parameters of the effect mediated through self-criticism $\left(\mathrm{M}_{2}\right)$ were $\mathrm{a}_{2} \mathrm{~b}_{2}$ coefficient=1.27, $\mathrm{SE}=0.60,95 \% \mathrm{CI} 0.20$ to 2.63 . The parameters of total effects were: coefficient $=1.26, \mathrm{SE}=0.61,95 \%$ CI 0.17 to 2.80 .

In both cases, these models indicate that self-criticism is a mediating variable in the relationship between attachment (both individual dimensions: anxiety and avoidance) and depressive symptoms. However, the dependency level does not have a mediating role in the attachment-depressive symptoms association (95\% CI includes the zero value). Higher levels of anxiety and avoidance appear to generate a more self-critical interaction style which results in more depressive symptomatology.

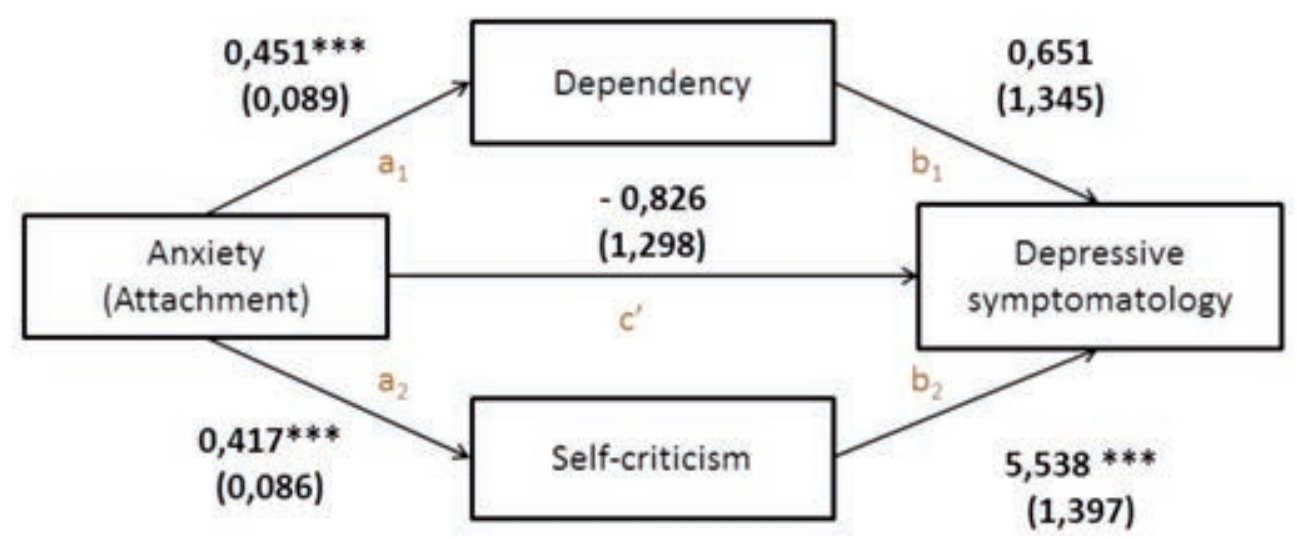

Figure 2. Mediational role of dependency and self-criticism in the relationship between attachment/anxiety and depressive symptoms. The figure was constructed based on the following regression models: $\mathrm{Y}=\mathbf{2 6 . - 0 . 8 3} \times \mathbf{X}+\mathbf{0 . 6 5} * \mathrm{M}_{1}+\mathbf{5 . 5 4} * \mathrm{M}_{2}, R^{2}=.22$; $F(3,66)=6.39, \mathrm{P}<.001 ; M_{1}=-2.12+0.45 * X, R^{2}=.27 ; F(1,68)=25.58, P<.001 ; M_{2}=-1.41+0.42 * X, R^{2}=.26 ; F(1,69)=23.51, P<.001$. 


\section{Interactional effects}

The results in model 1 (Table 3) indicate that the effect of the attachment dimensions (avoidance and anxiety), the size of the social network, and their interactions account for $10 \%$ (adjusted $R^{2}$ ) of the variability of the depressive symptoms and that none of the individual predictors were significant.

However, when considering the level of satisfaction with the social network (model 2), the results obtained reveal a significant effect. Model 2 accounts for $16 \%$ of the variability of depressive symptoms, and a significant 3way interaction between network satisfaction and both attachment dimensions (anxiety and avoidance) is observed.

Based on model 2 predictors, four simple regression equations were estimated (Figure 4). Their results indicated that only one of these equations is statistically significant. Specifically, when the level of satisfaction with one's social network is low and the anxiety dimension of attachment is high, as avoidance increases in the attach- ment scale, depressive symptoms increase as well $(\beta=10.54, \mathrm{SE}=4.26, \mathrm{P}=.02)$.

\section{Discussion}

Results show that self-criticism is related to depression, and that anxious attachment is related to both selfcriticism and dependency, while avoidant attachment is associated with self-criticism. Satisfaction with the social network relates inversely to depressive symptomatology. Thus, it can be empirically stated that only the self-criticism variable had a mediating role between attachment style and depression. Furthermore, results show that only in the condition of higher attachment anxiety and low social network satisfaction was avoidant attachment related to more intense depressive symptomatology.

Results showing that depression was related only marginally to avoidant attachment were unexpected, since previous research indicated that both attachment styles

Table 2. Means, standard deviations and correlations of study variables.

\begin{tabular}{|c|c|c|c|c|c|c|c|c|c|c|c|}
\hline & $\mathbf{N}$ & $\mathbf{M}$ & SD & 2 & 3 & 4 & 5 & 6 & 7 & 8 & 9 \\
\hline Gender & 70 & 0.17 & 0.38 & 0.00 & -0.10 & -0.23 & 0.00 & 0.12 & -0.22 & -0.10 & -0.02 \\
\hline Age & 70 & 41.47 & 12.91 & & $-0.23^{\mathrm{f}}$ & -0.07 & $-0.40 * * *$ & -0.05 & -0.04 & -0.12 & 0.17 \\
\hline Depression & 70 & 25.83 & 9.81 & & & 0.15 & $0.47 * * *$ & $0.23 £$ & 0.19 & -0.09 & -0.03 \\
\hline Dependency & 70 & -0.03 & 0.93 & & & & $0.26^{*}$ & 0.07 & $0.52 * * *$ & 0.18 & -0.12 \\
\hline Self-criticism & 70 & 0.52 & 0.89 & & & & & $0.31 * *$ & $0.51 * * *$ & -0.11 & -0.15 \\
\hline Avoidance (attachment) & 70 & 3.48 & 1.06 & r & & & & & 0.20 & $-0.31 *$ & $-0.31 *$ \\
\hline Anxiety (attachment) & 70 & 4.64 & 1.08 & & & & & & & -0.20 & -0.25 \\
\hline Social network size & 63 & 2.56 & 1.27 & & & & & & & & 0.09 \\
\hline Social network satisfaction & 52 & 5.20 & 1.02 & & & & & & & & \\
\hline
\end{tabular}

$\mathrm{M}$, mean; $\mathrm{SD}$, standard deviation; $2-9$, pair-wise correlations. ${ }^{* * *} \mathrm{P}<.001 ; * * \mathrm{P}<.01 ;{ }^{*} \mathrm{P}<.05 ;{ }^{\natural} \mathrm{P}<.053$.

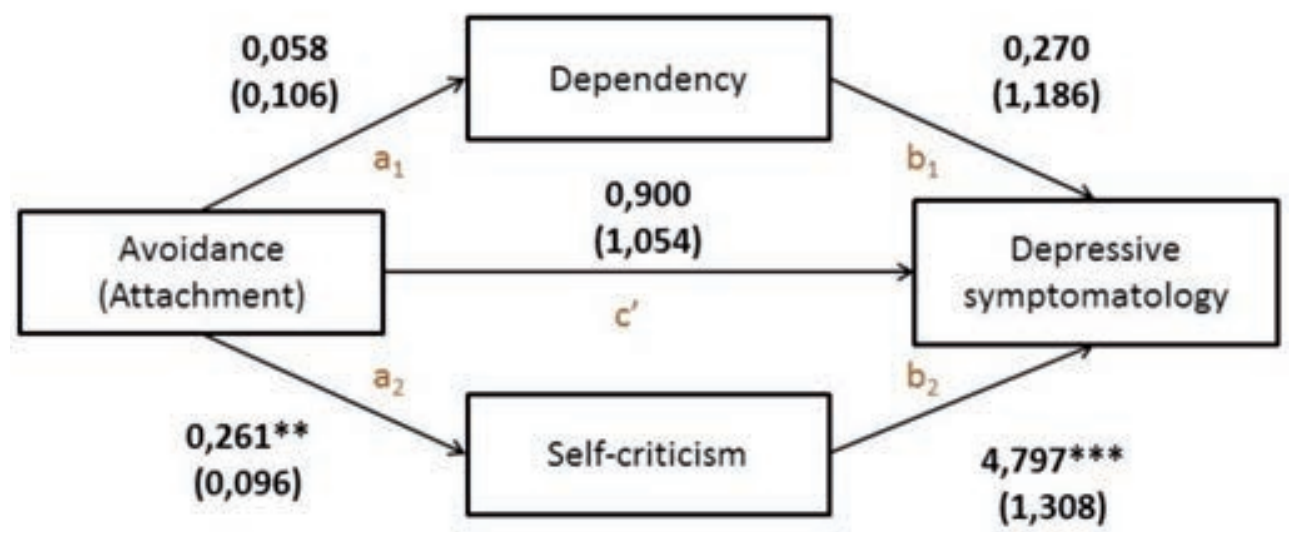

Figure 3. Mediational role of dependency and self-criticism in the relationship between attachment/avoidance and depressive symptoms. The figure was constructed based on the following regression models: $Y=20.19-090 * X+0.27 * M_{1}+4.80 * M_{2}, R^{2}=.23$; $F(3,66)=6.53, \mathrm{P}<.001 ; \mathrm{M}_{1}=-.23+0.06 * \mathrm{X}, R^{2}=.004 ; F(1,68)=0.30, \mathrm{P}=.59 ; \mathrm{M}_{2}=-0.38+0.26 * \mathrm{X}, R^{2}=.10 ; F(1,69)=7.38, \mathrm{P}<.01$. 
were linked to depression (e.g. Bifulco, Moran, Ball, \& Bernazzani, 2002; López, Mauricio, Gormley, Simko \& Berger, 2001; Wei, Heppner, Rusell \& Young, 2006). This result may be explained by our small sample size, and will require further empirical research.

The significant relationship between depression and self-criticism coincides with what Luyten et al. (2007) found when they linked the two types of personality styles with the severity of depressive symptoms: the correlations were higher for self-criticism than for dependency.

On the other hand, when looking at both maladaptive attachment styles (anxious and avoidant), it was found that they were both associated with the self-critical personality style, but that only the anxious attachment style was linked with the dependent style. This result is consistent with Reis and Grenyer's (2002) previous findings. It seems that adult attachment insecurity provides a viable path to distress and depression (Zuroff \& Fitzpatrick, 1995), since both attachment styles are associated with negative models of self. Nevertheless, the fact that the avoidant adult attachment style was specifically related to self-criticism can be understood taking into account that this attachment style is characterized by excessive independence, distance from relationships, and a low sense of self-worth, traits which resemble introjective experiences.

In the social dimension, it was found that only the avoidant attachment style was linked with social support. This result was expected, since the avoidant attachment style is characterized by fear of intimacy, discomfort with closeness, and a negative working model of others (Pietromonaco \& Barrett, 2000); therefore, it would be natural for individuals with this style to be unsatisfied with their social network. No significant relation was found between social support and anxious attachment. As Pietromonaco \& Barrett (2000) note, this may be due to the fact that individuals with anxious attachment develop negative internal working models of self, thus perceiving less self-efficacy and tending to perceive others as a source of support.

The analysis of the relation between attachment, personality style, and depression revealed that patients with higher levels of avoidant or anxious attachment establish a more self-critical interaction style, which translates into a greater presence of depressive symptomatology. This result confirms previous evidence showing that insecure adult attachment styles (anxious or avoidant) have an impact on depression, especially when self-criticism is mediating this relationship.

After the social component was included in the analysis, results showed that, when there is low social support satisfaction and highly anxious attachment, as avoidant attachment increases, the level of depression increases as well. This reminds us of a point made by Shahar in 2004: some interactional styles (e.g. self-criticism) use behaviors (e.g. criticizing others) that generate similar reactions in others (e.g. introjected self-criticism) and create conditions that, in turn, sustain their interaction styles (e.g. rejection) which can lead to depression.

However, the main finding of the study is probably the power of self-criticism as a personality style. This is observed when considering the relationship between this aspect and both attachment styles and also when it is regarded as a mediational variable between attachment styles and depression. Blatt (1995) and others (Shahar, 2001; Zuroff, Mongrain, \& Santor, 2004; Shahar, Blatt, \& Zuroff, 2007) have pointed out that this style is an in-

Table 3. Predictors of depressive symptomatology: attachment dimensions, social network dimension, and their interactions.

\begin{tabular}{|c|c|c|c|c|c|c|}
\hline & \multicolumn{3}{|c|}{ Model 1} & \multicolumn{3}{|c|}{ Model 2} \\
\hline & B & Error & $95 \% \mathrm{CI}$ & $\boldsymbol{B}$ & Error & $95 \% \mathrm{CI}$ \\
\hline Constant & 25.87 & $1.38 * * *$ & 23.1028 .63 & 26.40 & $1.75 * * *$ & 22.8729 .92 \\
\hline Sex & 0.39 & 3.17 & -5.976 .74 & -1.17 & 3.70 & -8.626 .29 \\
\hline Age & -0.16 & 0.10 & -0.350 .04 & -0.24 & $0.11^{*}$ & $-0.47-0.01$ \\
\hline A & 1.48 & 1.26 & -1.064 .01 & 0.99 & 1.56 & -2.154 .15 \\
\hline B & 1.40 & 1.31 & -1.234 .03 & 1.12 & 1.67 & -2.254 .97 \\
\hline Size social network & 0.57 & 1.09 & -1.612 .75 & - & - & \\
\hline Satisfaction social network & - & - & & -0.18 & 2.37 & -4.964 .61 \\
\hline$A * B$ & -0.44 & 1.27 & -2.992 .11 & 2.14 & 1.81 & -1.525 .79 \\
\hline$A * C$ & 0.09 & 0.88 & -1.681 .85 & -0.94 & 2.17 & -5.323 .44 \\
\hline $\mathrm{B}^{*} \mathrm{C}$ & -1.04 & 1.09 & -3.221 .15 & 0.23 & 1.60 & -2.993 .44 \\
\hline$A * B * C$ & -1.43 & 0.89 & -3.210 .34 & -5.62 & $1.99 * *$ & $-9.64-1.61$ \\
\hline
\end{tabular}

$\mathrm{CI}$, confidence interval; $\mathrm{A}$, attachment avoidance; $\mathrm{B}$, attachment anxiety; $\mathrm{C}$, size/satisfaction social network. Model 1 adjustment indicators $R^{2}$ adjustment $=0.10$; $\mathrm{F}(9.55)=1.74, \mathrm{P}=.10, \mathrm{~N}=65$; Model 2 adjustment indicators: $R^{2}$ adjustment $=0.16 ; \mathrm{F}(9.43)=2.07, \mathrm{P}=0.054 ; \mathrm{N}=53 . * * * \mathrm{P}<.001 ; * * \mathrm{P}<.01 ; * \mathrm{P}<.05$. 
dicator of a serious depression risk and that it is a sign of active vulnerability. In other words, self-critical individuals generate both failure-related and interpersonally stressful events (e.g. Shahar, Joiner, Zuroff, \& Blatt, 2004), with this style being linked to a failure to generate positive life events and social support (Mongrain, 1998; Priel \& Besser, 2000).

\section{Conclusions}

Overall, the present results may have implications for the integration and advancement of theories of depression. For instance, they further stress the notion that depression is a multidimensional phenomenon. Attachment, self-criticism, dependency, and social support are variables that

\section{Low satisfaction with Social Support}

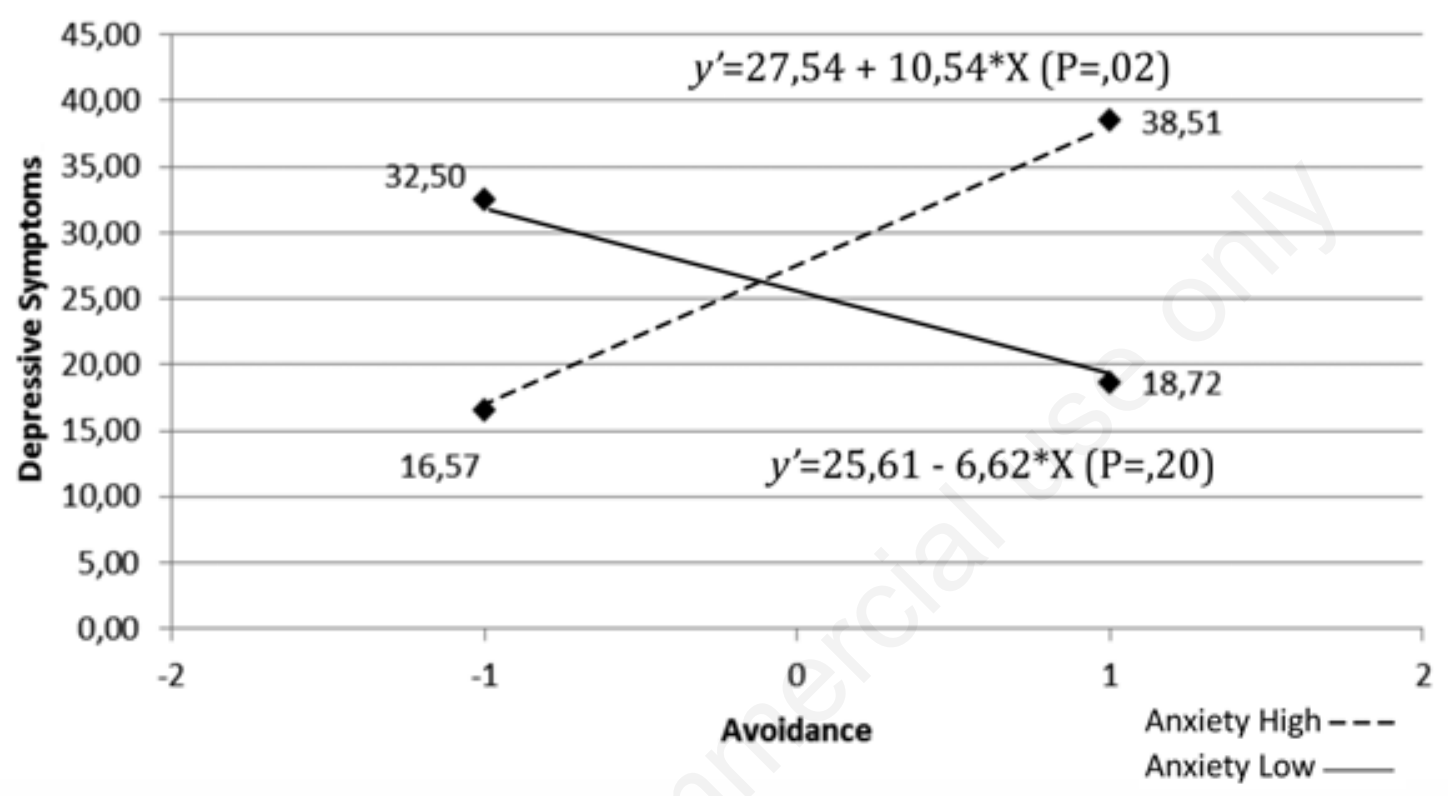

\section{High satisfaction with Social Support}

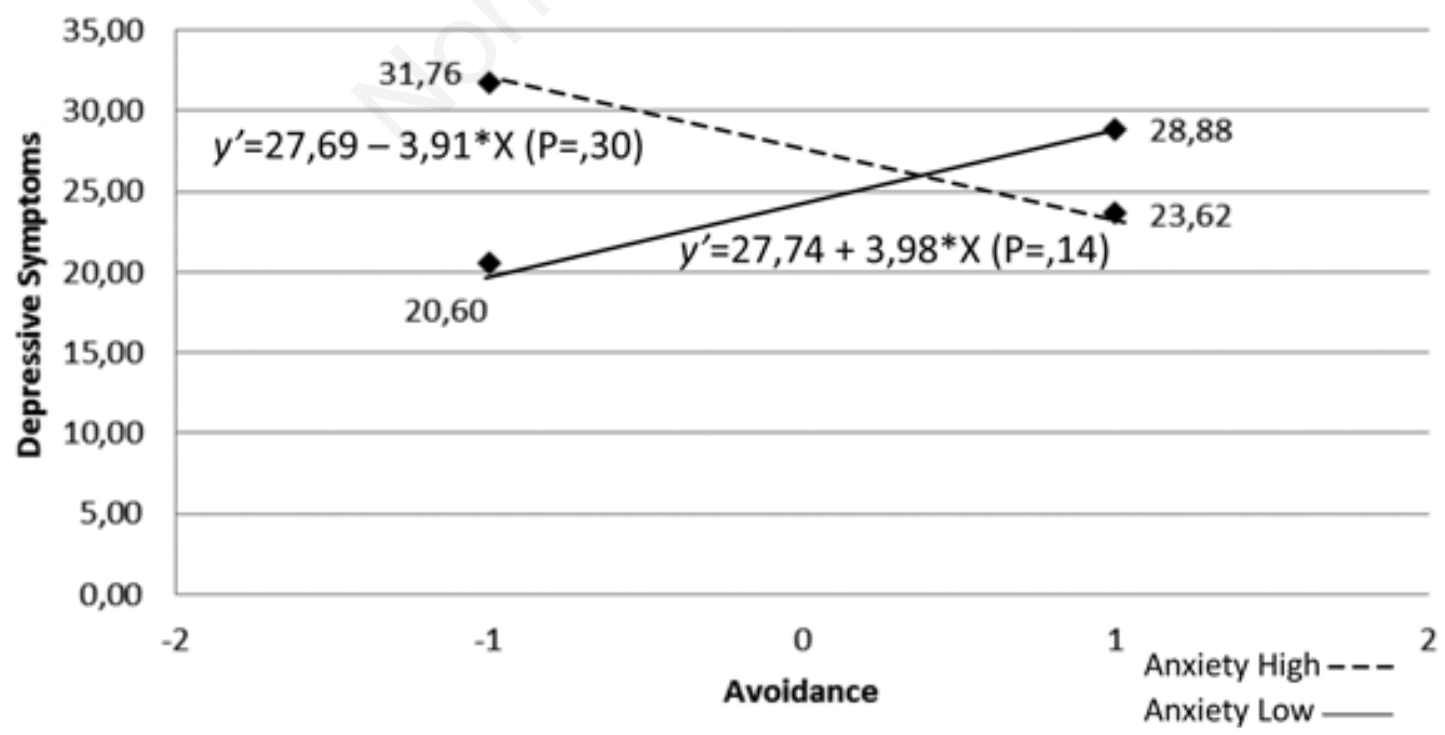

Figure 4. Interaction between the level of anxiety, avoidance and satisfaction with social network as predictors of the level of depressive symptomatology. 
comprise this multidimensionality and should therefore not be studied in isolation.

Nevertheless, several limitations of this study must be noted. First, because of its cross-sectional design, it was not possible to develop directional hypotheses. Future research should consider using longitudinal designs to better understand possible causal relations among these variables. Second, the sample size is small and subjects are mainly women. The high prevalence of women is consistent with the high prevalence of depression in this gender (e.g. Albert, 2015), besides the fact that they tend to seek more mental health professionals than men (e.g. Mackenzie, Gekoski, \& Knox, 2006). Third, there are many variables that can relate with attachment insecurities that have not been measured in this study, for example personality traits or factors. Finally, to ensure the clinical usefulness of these findings, it is necessary to analyze the evolution of the variables assessed in this study throughout therapeutic processes.

\section{References}

Aiken, L.S., \& West, S.G. (1991). Multiple regression: testing and interpreting interactions. Thousand Oaks, CA: Sage. doi: 10.1037/0021-9010.84.6.897

Albert, P.R. (2015). Why is depression more prevalent in women? Journal of Psychiatry \& Neuroscience, 40(4), 219221. doi: 10.1503/jpn. 150205

Alden, L.E., \& Bieling, P.J. (1996). Interpersonal convergence of personality constructs in dynamic and cognitive models of depression. Journal of Research in Personality, 30, 6075. doi: 10.1006/jrpe.1996.0004

Alvarado, R., Vega, J., Sanhueza, G., \& Muñoz, M. (2005). Evaluación del programa para la detección, diagnostico y tratamiento integral de la depresión en atención primaria, en Chile [Program evaluation for the detection, diagnosis and treatment of depression in primary care in Chile]. Revista Panamericana de Salud Publica, 18, 278-286. doi: 10.1590/S1020-49892005000900008

Anez, L., \& Paris, M. (1999). Traducción al español del Depressive Experience Questionnaire (DEQ) [Spanish translation of the Depressive Experiences Questionnaire]. New Haven, CT, USA: University of Yale.

Arieti, S., \& Bemporad, J.R. (1980). The psychological organization of depression. American Journal of Psychiatry, 137, 1360-1365.

Beck, A.T. (1967). Depression: clinical, experimental, and theoretical aspects. New York: Harper \& Row.

Beck, A.T., Ward, C.H., Mendelson, M., Mock, J.E., \& Erbaugh. J. (1961). An inventory of measuring depression. Archives of General Psychiatry, 4, 561-585. doi: 10.1001/archpsyc.1961.01710120031004

Belsher, G., \& Costello, C.G. (1991). Do confidants of depressed women provide less social support than confidants of nondepressed women? Journal of Abnormal Psychology, 100, 516-525. doi: 10.1037/0021-843X.100.4.516

Bifulco, A., Moran, P.M., Ball, C., \& Bernazzani, O. (2002). Adult attachment style I. Its relationship to clinical depres- sion. Social Psychiatry and Psychiatric Epidemiology, 37, 50-59. doi: $10.1007 / \mathrm{s} 127-002-8215-0$

Blatt, S.J. (1974). Levels of object representation in anaclitic and introjective depression. Psychoanalytic Study of the Child, 29, 107-157.

Blatt, S.J. (1995). The destructiveness of perfectionism: implications for treatment of depression. American Psychologist, 50, 1003-1020. doi: 10.1037/0003-066X.50.12.1003

Blatt, S.J., D’Afflitti, J.P., \& Quinlan, D.M. (1976). Experiences of depression in normal young adults. Journal of Abnormal Psychology, 85, 383-389. doi: 10.1037/0021-843X.85.4.383

Blatt, S.J., \& Homann, E. (1992). Parent-child interaction in the etiology of dependent and self-critical depression. Clinical Psychology Review, 12, 47-91. doi: 10.1016/02727358(92)90091-L

Blatt, S.J., Quinlan, D.M., Chevron, E.S., McDonald, C., \& Zuroff, D. (1982). Dependency and self-criticism: psychological dimensions of depression. Journal of Consulting and Clinical Psychology, 50, 113-124. doi: 10.1037/0022006X.50.1.113

Brennan, K.A., Clark, C.L., \& Shaver, P.R. (1998). Self-report measurement of adult romantic attachment: an integrative overview. In J.A. Simpson \& W.S. Rholes (Eds.), Attachment theory and close relationships (pp. 46-76). New York: Guilford Press.

Coyne, J.C. (1976a). Depression and the response of others. Journal of Abnormal Psychology, 85, 186-193. doi: 10.1037/0021-843X.85.2.186

Coyne, J.C. (1976b). Toward an interactional description of depression. Psychiatry: Journal for the Study of Interpersonal processes, 39, 28-40. doi: 10.1080/00332747.1976.11023874

Dinger, U., Barrett, M.S., Zimmermann, J., Schauenburg, H., Wright, A.G.C., Renner, F., ... Barber, J.P. (2014). Interpersonal problems, dependency, and self-criticism in major depressive disorder. Journal of Clinical Psychology, 00(0), 1-12. doi: $10.1002 /$ jclp. 22120

Gnilka, P.B., Ashby, J.S., \& Noble, C.M. (2013). Adaptive and maladaptive perfectionism as mediators of adult attachment styles and depression, hopelessness, and life satisfaction. Journal of Counseling \& Development, 91(1), 78-86. doi: 10.1002/j.1556-6676.2013.00074.x

Guzmán, M. \& Contreras, P. (2012). Estilos de apego en relaciones de pareja y su asociación con la satisfacción marital [Attachment styles in couples and its association with marital satisfaction]. Psykhe, 21, 69-82. doi: 10.4067/S071822282012000100005

Henrich, C.C., Blatt, S.J., Kuperminc, G.P., Zohar, A., \& Leadbeater, B.J. (2001). Levels of interpersonal concerns and social functioning in early adolescent boys and girls. Journal of Personality Assessment, 76, 48-67. doi: 10.1207/S15327752 JPA7601 3

Jinyao, Y., Xiongzhao, Z., Auerbach, R.P., Gardiner, C.K., Lin, C., Yuping, W., \& Shuqiao, Y. (2012), Insecure attachment as predictor of depressive and anxious symptomatology. Depress Anxiety, 29, 789-796. doi: 10.1002/da.21953

Joiner, T.E. (2002). Depression in its interpersonal context. In I.H. Gotlib \& C.L. Hammen (Eds.), Handbook of depression (pp. 295-313). New York, NY: Guilford Press.

Kessler, R.C. (1997). The effects of stressful life events on depression. Annual Review of Psychology, 48, 191-214. doi: 10.1146/annurev.psych.48.1.191

Kessler, R.C., \& Bromet, E.J. (2013). The epidemiology of depression across cultures. Annual Review of Public Health, 34, 
119.138. doi: 10.1146/annurev-publhealth-031912-114409

Lopez, F.G., Mauricio, A.M., Gormley, B., Simko, T., \& Berger, E. (2001). Adult attachment orientations and college student distress: the mediating role of problem coping styles. Journal of Counseling \& Development, 79, 459-464. doi: 10.1002/j.1556-6676.2001.tb01993.x

Luyten, P., Sabbe, B., Blatt, S.J., Meganck, S., Jansen, B., De Grave, C., ..., \& Corveleyn, J. (2007). Dependency and selfcriticism: relationship with major depressive disorder, severity of depression, and clinical presentation. Depression and Anxiety, 24(8), 586-596. doi: 10.1002/da.20272

Mackenzie, C.S., Gekoski, W.L., \& Knox, V.J. (2006). Age, gender, and the underutilization of mental health services: the influence of help-seeking attitudes. Aging \& Mental Health, 10(6), 574-582. doi: 10.1080/13607860600641200

MacKinnon, D.P. (2008). Introduction to statistical mediation analysis. New York, NY: Erlbaum.

Mallinckrodt, B., \& Wei, M. (2005). Attachment, social competencies, social support, and psychological distress. Journal of Counseling Psychology, 52, 358-367. doi: 10.1037/00220167.52.3.358

McCarthy G. (1999) Attachment style and adult love relationships and friendships: a study of a group of women at risk of experiencing relationship difficulties. Psychology and Psychotherapy, 72: 305-321. doi: 10.1348/000711299160022

Mikulincer, M., \& Shaver, P.R. (2007). Attachment in adulthood: structure, dynamics, and change. New York, NY: The Guilford Press.

Mongrain, M. (1998). Parental representations and support-seeking behaviors related to dependency and self-criticism. Journal of Personality, 66(2), 151-173. doi: 10.1111/14676494.00007

Paykel, E.S. (2003). Life events and affective disorders. Acta Psychiatrica Scandinavica, 108 (Suppl. 418), 61-66. doi: 10.1034/j.1600-0447.108.s418.13.x

Pietromonaco, P.R., \& Barrett, L.F. (2000). The internal working models concept: what do we really know about the self in relation to others? Review of General Psychology, 4, 155157. doi: 10.1037/1089-2680.4.2.155

Preacher, K.J., \& Hayes, A.F. (2008). Asymptotic and resampling strategies for assessing and comparing indirect effects in multiple mediator models. Behavior Research Methods, 40, 879-891. doi: 10.3758/BRM.40.3.879

Priel, B., \& Besser, A. (2000). Dependency and self-criticism among first-time mothers: The roles of global and specific support. Journal of Social and Clinical Psychology, 19, 437-450. doi: 10.1521/jscp.2000.19.4.437

Reis, S., \& Grenyer, B.F.S. (2002). Pathways to anaclitic and introjective depression. Psychology and Psychotherapy, 75, 445-459. doi: 10.1348/147608302321151934

Rost, R., \& Dagnino, P. (2011). Traducción a Chile del Depressive Experience Questionnaire (DEQ) [Chilean translation of the Depressive Experiences Questionnaire]. Santiago, Chile: Pontificia Universidad Catolica de Chile.
Santander, J., Romero, M.I., Hitschfeld, M.J., \& Zamora, V. (2011). Prevalencia de ansiedad y depresión entre los estudiantes de medicina de la Pontificia Universidad Católica de Chile [Anxiety and depression prevalence within medical students of Pontificia Universidad Católica de Chile]. Revista Chilena de Neuro-Psiquiatria, 49, 47-55. doi: 10.4067/S0717-92272011000100006

Sarason, I.G., Sarason, B.R., Shearin, E.N., \& Pierce, G.R. (1987). A brief measure of social support: Practical and theoretical implications. Journal of Social and Personal Relationships, 4, 497-510. doi: 10.1177/0265407587044007

Scheff, T.J. (2001). Shame and community: social components in depression. Psychiatry, 64(3), 212-224.

Shahar, G. (2001). Personality, shame, and the breakdown of social ties: The voice of quantitative depression research. Psychiatry, 64, 218-229. doi: 10.1521/psyc.64.3.228.18463

Shahar, G. (2004). Transference-countertransference: where the (political) action is. Journal of Psychotherapy Integration, 14, 371-396. doi: 10.1037/1053-0479.14.4.371

Shahar, G., Blatt, S.J., \& Zuroff, D.C. (2007). Satisfaction with social relations buffers the adverse effect of (mid-level) self-critical perfectionism in brief treatment for depression. Journal of Social and Clinical Psychology, 26(5), 540-555. doi:10.1521/jscp.2007.26.5.540

Shahar, G., Joiner, T.E. Jr., Zuroff, D.C., \& Blatt, S.J. (2004). Personality, interpersonal behavior, and depression: Co-existence of stress-specific moderating and mediating effects. Personality and Individual Differences, 36, 1583-1596. doi. 10.1016/j.paid.2003.06.006

Wei, M., Heppner, P.P., Russell, D.W., \& Young, S.K. (2006). Maladaptive perfectionism and ineffective coping as mediators between attachment and future depression: a prospective analysis. Journal of Counseling Psychology, 53(1), 67-79. doi: 10.1037/0022-0167.53.1.67

WHO (1992). The ICD-10 classification of mental and behavioural disorders: clinical descriptions and diagnostic guidelines. Geneva, Switzerland: World Health Organization.

WHO (2012). World Health Assembly Resolution 65.4: Global burden of mental disorders and the need for a comprehensive, coordinated response from health and social sectors at the country level. Geneva, Switzerland: World Health Organization.

Zubin, J., \& Spring, B. (1977). Vulnerability: a new view of schizophrenia. Journal of Abnor- mal Psychology, 86, 103126. doi: 10.1037/0021-843X.86.2.103

Zuroff, D.C., \& Fitzpatrick, D.A. (1995). Depressive personality styles: implications for adult attachment. Personality and Individual Differences, 18, 253-265. doi: 10.1016/01918869(94)00136-G

Zuroff, D.C., Mongrain, M., \& Santor, D. (2004). Conceptualizing and measuring personality vulnerability to depression: comment on Coyne and Whiffen (1995). Psychological Bulletin, 130(3), 489-511. doi: 10.1037/0033-2909.130.3.489 